\title{
Kinetic Basis for the Voltage-dependent Inhibition of N-type Calcium Current by Somatostatin and Norepinephrine in Chick Sympathetic Neurons
}

\author{
Andre Golard and Steven A. Siegelbaum \\ Center for Neurobiology and Behavior, Department of Pharmacology, Howard Hughes Medical Institute, Columbia \\ University, New York, New York 10032
}

Neurotransmitter inhibition of calcium currents $\left(I_{c a}\right)$ can be relieved by large depolarizing prepulses. This effect has been postulated to be due either to the voltage-dependent unbinding of an inhibitory molecule from the channel or to a slow voltage-dependent gating step intrinsic to the modulated channel. According to the first hypothesis, the rate of reinhibition (reblock) following a depolarizing prepulse should depend on the concentration of active inhibitory molecules and thus should increase with the extent of inhibition. To distinguish between these models we examined the actions of norepinephrine (NE) and somatostatin (SS) on highthreshold calcium currents in chick sympathetic ganglia, using whole-cell voltage-clamp methods. As previously described in other systems, both NE and SS inhibit $\omega$-conotoxin-sensitive $\mathrm{N}$-type $\mathrm{Ca}^{2+}$ current in a voltage-dependent manner. Portussis toxin (PTX) pretreatment prevents the inhibition of the current, while replacing GTP in the patch pipette with GTP- $\gamma$-S results in irreversible inhibition, consistent with the involvement of a PTX-sensitive G-protein. The inhibitory responses to NE and SS are not additive, suggesting that they act at a common locus. The inhibitory response to repeated applications of NE or SS desensitizes, with little evidence for cross desensitization. The inhibition of $I_{\mathrm{Ca}}$ is relieved by a $15 \mathrm{msec}$ prepulse to $+100 \mathrm{mV}$. Following repolarization to $-\mathbf{8 0} \mathrm{mV}, I_{\mathrm{ca}}$ slowly reblocks. During prolonged applications of NE or SS the extent of inhibition decreases due to desensitization and reblock kinetics are significantly slowed (time constant increases from $60 \mathrm{msec}$ to $>100$ msec for both NE and SS). These results are well fit by a quantitative model in which the kinetics of reblock reflect the binding of an inhibitory molecule to the channel.

[Key words: $\mathrm{Ca}^{2+}$ channel, GTP-binding proteins, norepinephrine, somatostatin, sympathetic neurons, desensitization]

High-threshold calcium currents in both peripheral and central neurons are inhibited rapidly by a variety of neurotransmitters (Dunlap and Fischbach, 1981; Forscher and Oxford, 1985; Dolphin and Scott, 1987; Ewald et al., 1988; Lipscombe et al., 1989;

\footnotetext{
Received Nov. 23, 1992; revised Mar. 2, 1993; accepted Mar. 18, 1993.

We thank Dr. Lorna Role for helpful advice, Drs. Bruce Bean and Linda Boland for providing us with their manuscript before publication, and Chuck Lamb for help in preparing the figures. This work was supported in part by a grant from the NIH (NS29832).

Correspondence should be addressed to Dr. Andre Golard, Center for Neurobiology and Behavior, Howard Hughes Medical Institute, 722 West 168 Street, New York, NY 10032.

Copyright (C) 1993 Society for Neuroscience $0270-6474 / 93 / 133884-11 \$ 05.00 / 0$
}

Bley and Tsien, 1990; see Dolphin, 1991, for review). One characteristic feature of these inhibitory actions is that they often show a marked voltage dependence. The inhibition is negligible at very depolarized potentials (Bean, 1989; Ikeda and Schofield, 1989) and can be relieved at less positive voltages by strong depolarizing prepulses (Elmslie et al., 1990). Following repolarization back to the resting potential, the calcium channels then become slowly reinhibited or reblocked (Elmslie et al., 1990). In addition, the time course of calcium current activation often exhibits a pronounced slowing in the presence of inhibitory transmitter (Marchetti et al., 1986).

There is now general agreement that most of these rapid, voltage-dependent inhibitory actions of neurotransmitters on calcium current are mediated through activation of pertussis toxin (PTX)-sensitive G-proteins (Dolphin, 1991; Hille, 1992). However, the mechanism by which G-protein activation is linked to $\mathrm{Ca}^{2+}$ channel modulation is more controversial and may involve either activation of protein kinase $C$ (PKC) or a direct G-protein-channel interaction. Activation of PKC is thought to underlie inhibition of calcium channels by norepinephrine (NE) in chick dorsal root ganglion (DRG) neurons (Rane and Dunlap, 1986) and neuropeptide $Y$ in rat DRG neurons (Rane et al., 1989). In rat hippocampal neurons PKC activation has also bcen shown to inhibit $\mathrm{Ca}^{2+}$ current (Doerner et al., 1988). In contrast, a number of inhibitory transmitter actions do not appear to involve $\mathrm{PKC}$, since $\mathrm{PKC}$ activation does not produce the characteristic voltage-dependent inhibition of calcium current seen with these agonists (Kasai and Aosaki, 1989; Bley and Tsien, 1990; Plummer et al., 1991).

Evidence in support of a direct G-protein-channel interaction is based on several lines of evidence. First, a number of studies have failed to identify any second messenger that mimics the action of the transmitters. Second, transmitter-dependent inhibition of $\mathrm{Ca}^{2+}$ current can be quite rapid, with an onset occurring in $50 \mathrm{msec}$, which is faster than most known second messenger-mediated events (Bean, 1989). Third, application of transmitter to the bath fails to inhibit $\mathrm{Ca}^{2+}$ channels in cellattached patches, arguing against a freely diffusible second messcnger and supporting a membranc-delimited mechanism of G-protein action (Forscher et al., 1986; Lipscombe et al., 1989). Recent experiments in rat sympathetic neurons suggest that a single transmitter may recruit multiple modulatory pathways involving both second messenger-dependent and second messenger-independent mechanisms (Beech et al., 1992).

Two basic models have been proposed to account for the voltage-dependent inhibition of calcium currents by transmitters (Bean, 1989; Kasai and Aosaki, 1989). Both Bean (1989; 
Boland and Bean, 1993) and Kasai and Aosaki (1989; Kasai, 1992) proposed that calcium channels exist in two gating modes: a willing mode that displays normal rapid activation kinetics and is the predominant gating mode in the absence of transmitter, and a reluctant mode induced by inhibitory transmitters, in which strong depolarizations are required to activate the channel. Transitions between willing and reluctant modes are thought to reflect the binding and unbinding of some inhibitory molecule, perhaps the G-protein itself, to the channel. The major difference in the two models concerns the time scale of these latter reactions. According to Kasai and Aosaki (1989), these rates are rather slow, so typical depolarizations are too short to allow substantial conversion between willing and reluctant modes. Thus, Kasai and Aosaki (1989) proposed that the slowing of activation of calcium current with inhibitory transmitter reflects the slow intrinsic gating kinetics of channels in the reluctant mode. These slow $\mathrm{Ca}$ current kinetics should show little dependence on the concentration of the inhibitory molecule. In contrast, Bean has proposed that the willing-reluctant transitions occur on a fairly rapid time scale that is similar to that of $\mathrm{Ca}$ current measurements. Thus, the slow $\mathrm{Ca}$ current kinetics largely reflect the rate of transitions between reluctant and willing modes of gating and so should depend on the concentration of active inhibitory molecules.

Several groups have now tried to distinguish between these two models by determining the extent to which the slow $\mathrm{Ca}$ current kinetics depend on the concentration of the inhibitory molecule. Kasai and Aosaki (1989) varied inhibitory molecule concentration by varying the concentration of the inhibitory agonist 2-chloroadenosine in chick sensory neurons. They found that the slow time constant of $\mathrm{Ca}$ current activation during a depolarization showed no dependence on 2-chloroadenosine concentration, consistent with their model. More recently, Lopez and Brown (1991) examined the kinetic nature of Ca channel inhibition in rat sensory neurons by using GTP- $\gamma-\mathrm{S}$ to activate G-proteins directly. These authors measured the kinetics of reinhibition during a prolonged depolarization to $0 \mathrm{mV}$ following a strong depolarizing prepulse and found a good correlation between the kinetics of reblock and the extent of G-protein activation, supporting Bean's model. However, Elmslie and Jones (1992), in bullfrog sympathetic neurons, found that reblock kinetics at $0 \mathrm{mV}$ did not change with the extent of inhibition in response to different concentrations of leutinizing hormonereleasing hormone, in agreement with the model of Kasai and Aosaki.

Here, we further investigate the kinetic mechanism for voltage-dependent calcium current inhibition by studying the inhibitory actions of NE and somatostatin (SS) on calcium currents in chick sympathetic neurons. We have tried to distinguish between the above two models by comparing the kinetics of calcium current reblock at $-80 \mathrm{mV}$ with the extent of $\mathrm{Ca}^{2+}$ channel inhibition produced by NE alone, SS alone, or SS + NE. By measuring kinetics of reblock at a negative holding potential of $-80 \mathrm{mV}$, we avoid possible complications from $\mathrm{Ca}^{2+}$ channel activation and inactivation kinetics that complicate measurements of reblock kinetics at more positive potentials (cf. Kasai and Aosaki, 1989; Lopez and Brown, 1991; Elmslie and Jones, 1992). We have used the normal desensitization of the response to prolonged application of these transmitters as a means to vary the extent of inhibition. During desensitization, the rate of reblock is proportional to the extent of channel inhibition, consistent with the model proposed by Bean (1989), in which the slow $\mathrm{Ca}$ current kinetics induced by inhibitory transmitter reflect transitions between modulated and nonmodulated modes of gating.

\section{Materials and Methods}

Cell culture. Sympathetic neurons were prepared according to Role (1988). Lumbar sympathetic ganglia from embryonic day 11 chicks were incubated for $30 \mathrm{~min}$ in a phosphate-buffered medium containing $0.01 \%$ trypsin. The ganglia were triturated with a flame-polished Pasteur pipette and plated at a density of one chain (five to seven ganglia) per dish. The cells were maintained 7-14 d in Dulbecco's modified Eagle's medium supplemented with $10 \%$ horse serum, $2 \%$ chick embryo extract, $2 \mathrm{~mm}$ glutamine, penicillin $(50 \mathrm{U} / \mathrm{ml})$, streptomycin $(50 \mu \mathrm{g} / \mathrm{ml})$, and nerve growth factor $(0.1 \mu \mathrm{g} / \mathrm{ml})$.

Electrophysiology. Wholc-cell patch-clamp rccordings were performed at room temperature using a patch-clamp amplifier (EPC-7, List Electronics) in voltage-clamp mode. Before the recordings the culture dish was rinsed three times with a low-Ca solution containing (in $\mathrm{mM}$ ) $\mathrm{NaCl}, 138 ; \mathrm{KCl}, 5 ; \mathrm{MgCl}_{2}, 0.8 ; \mathrm{CaCl}_{2}, 0.5 ;$ HEPES, 15; glucose, 5; and TTX, 0.002 . The $\mathrm{pH}$ was adjusted to 7.35 with $\mathrm{NaOH}$, and glucose and TTX were added just before use. During the recording the neurons were locally superfused with a solution containing (in $\mathrm{mM}$ ) $\mathrm{NaCl}, 132 ; \mathrm{CaCl}_{2}$, 2.5; $\mathrm{MgCl}_{2}, 0.8$; HEPES, 10; tetraethylammonium (TEA), 10; 3,4-diaminopyridine (3,4-DAP), 3; glucose, 5; and TTX, 0.002. The $\mathrm{pH}$ was adjusted to 7.35 with $\mathrm{NaOH}$. Patch electrodes contained (in mM) Csmethanesulfonate, $100 ; \mathrm{CsCl}, 20 ; \mathrm{MgCl}_{2}, 2 ;$ EGTA, $10 ; \mathrm{CaCl}_{2}, 1$; and HEPES, 15. The pH was adjusted to 7.35 with CsOH. ATP ( $2 \mathrm{~mm})$ and GTP $(200 \mu \mathrm{M})$ were added just before use. Patch electrode resistances ranged from 2.5 to $4 \mathrm{M} \Omega$.

As typical peak $\mathrm{Ca}$ current magnitudes were 0.6-1.4 $\mathrm{nA}$ and input capacitance ranged from 20 to $50 \mathrm{pF}$, series resistance compensation was not used. To minimize space-clamp artifacts arising from $\mathrm{Ca}$ current contributions from distant neuronal processes, the culture dish contained the low-Ca solution (see above) and the normal Ca-containing recording solution was locally superfused onto the cell body and nearby processes (perfusion stream diameter was $150 \mu \mathrm{m}$ ). Our measurements of peak Ca current and $\mathrm{Ca}$ current kinetics during depolarizing pulses do not appear to be significantly affected by series resistance errors since we did not observe any change in Ca current kinetics during $\mathrm{Ca}$ current rundown where the magnitude of the peak $\mathrm{Ca}$ current was declining. However, the faster tail currents are likely to be distorted due to series resistance errors and so were not measured here.

Most chemicals were obtained through Sigma. Tissue culture media and supplements were obtained from GIBCO. Arachidonic acid (AA) was obtained from Nu-Chek-Prep. Pertussis toxin was obtained from Calbiochem. Somatostatin and norepinephrine were first dissolved in water and diluted in the superfusion buffer. Fatty acids were dissolved in dimethyl sulfoxide (DMSO) prior to dilution in the superfusion buffer. The final DMSO concentration was $0.1 \%$. At this concentration, DMSO had no effect on the Ca current.

Voltage-clamp protocols were generated using the pci.AMP software and TL-1 interface (Axon Instruments). Current traces were filtered at $1 \mathrm{kHz}$ using an 8-pole low-pass Bessel filter (Frequency Devices model 902), digitized on line at $5 \mathrm{kHz}$, and stored on an IBM-compatible PC.

The calcium currents were isolated by blocking sodium channels with TTX $(2 \mu \mathrm{M})$ and potassium channels with a combination of cesium (120 mM) in the internal solution and TEA (10 mM) and 3,4-DAP (3 mM) in the external solution. Under these conditions an apparent reversal of the current is observed at very depolarized potentials, presumably due to a permeability of the calcium channels to cesium ions (Lee and Tsien, 1982).

The membrane potential was held at $-80 \mathrm{mV}$ and depolarizing pulses were applied at a rate of $0.25 \mathrm{~Hz}$. Pulses at different voltages were applied to a locally superfused cell in the presence and the absence of norepinephrine ( $30 \mu \mathrm{M})$ and somatostatin $(30 \mathrm{nM})$. The gravity-fed superfusion was then switched to a solution containing $100 \mu \mathrm{M} \mathrm{LaCl}$. Records obtained in the presence of lanthanum were subtracted from both current records in absence or presence of transmitter.

\section{Results}

\section{SS and NE inhibit high-threshold calcium currents}

The calcium current in chick sympathetic neurons consists solely of high-voltage-activated currents, as described for other sympathetic neurons (Jones and Marks, 1989; Plummer et al., 1991). 
A 1 $0 \mathrm{mV}$
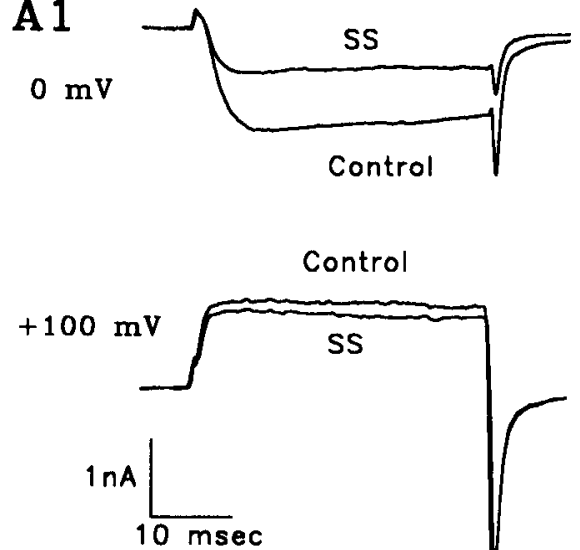

Control

Figure 1. Voltage-dependent inhibition of $\mathrm{Ca}^{2+}$ channel currents by SS $(A)$ and NE $(B)$. From a holding potential of $-80 \mathrm{mV}, 35 \mathrm{msec}$ test pulses were applied once every $4 \mathrm{sec}$. Records obtained in the presence of $100 \mu \mathrm{M} \mathrm{La}^{3+}$ were subtracted from all records. $A l$ and $B 1$, Current records shown for steps to 0 and $+100 \mathrm{mV}$ in absence (Control) or presence of transmitter. $A 2$ and $B 2$, Peak $I-V$ curves plotted in absence (open circles) and presence (solid circles) of transmitter. Responses to $30 \mathrm{~nm} \mathrm{SS}$ and $30 \mu \mathrm{M}$ NE.

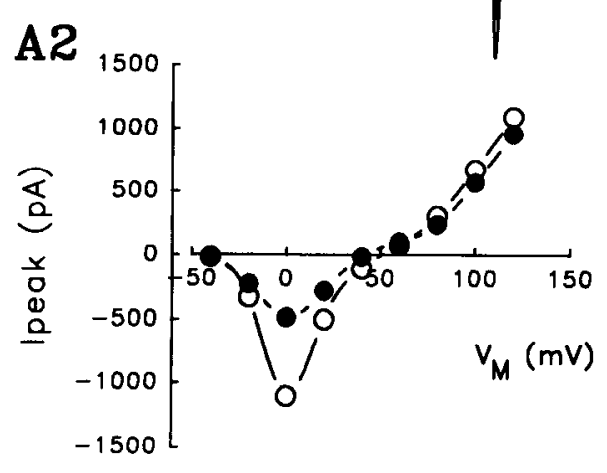

B 1
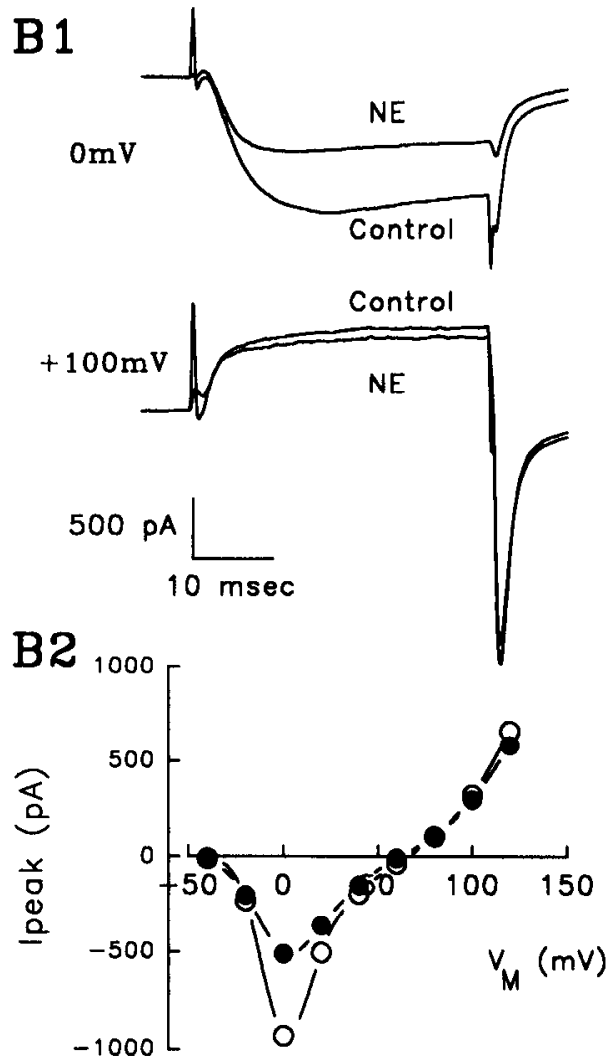

Figure I shows that an inward calcium current activated with depolarizations positive to $-40 \mathrm{mV}$, was maximum at $0 \mathrm{mV}$, and reversed direction at around $+50 \mathrm{mV}$. The outward current at strong depolarizations is presumably carried by the Cs present in the internal pipette solution (Lee and Tsien, 1982). The majority of calcium current in the chick sympathetic neurons appears to be carried by $\mathrm{N}$-type $\mathrm{Ca}^{2+}$ channels (Nowycky et al., 1985; Plummer et al., 1989). Thus, application of nifedipine $(10 \mu \mathrm{M})$, a blocker of L-type $\mathrm{Ca}^{2+}$ channels, had little effect on the $\mathrm{Ca}^{2-1}$ current elicited by a step to $0 \mathrm{mV}$ from a holding potential of $-60 \mathrm{mV}$ (mean decrease of $12.5 \pm 10.5 \%$, mean $\pm \mathrm{SEM} ; n=4)$. In contrast, application of $\omega$-conotoxin $(16 \mu \mathrm{M})$, a blocker of $\mathrm{N}$-type $\mathrm{Ca}^{2+}$ channels (McCleskey et al., 1987; Plummer et al., 1989), inhibited the total $\mathrm{Ca}^{2+}$ current by $70 \pm$ $7.6 \%(n=5$; data not shown).
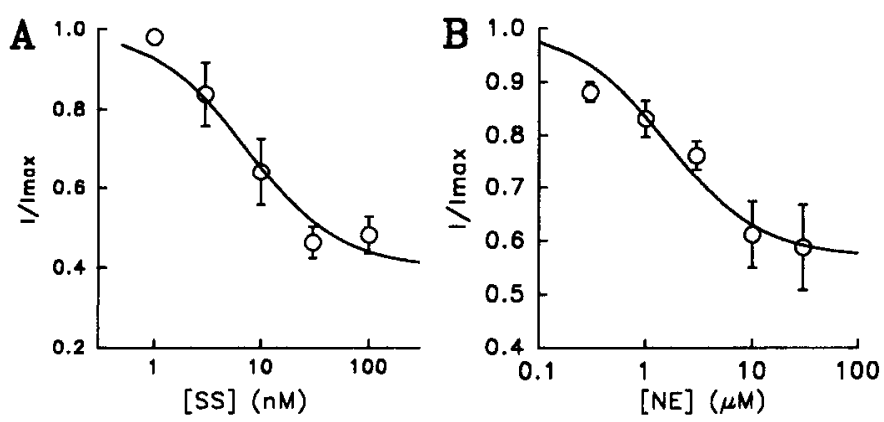

Figure 2. Concentration dependence of the inhibition of peak inward calcium current by SS and NE. Calcium currents measured with step to $0 \mathrm{mV}$. Each point is the average of three to nine records; error bars $=$ SD. Smooth curves are fits of single binding site equation given in Results.
Similar to results in rat and frog sympathetic neurons, we found that both SS and NE consistently inhibit the $\mathrm{Ca}^{2+}$ current in the chick sympathetic neurons (Fig. 1). $\mathrm{Ca}^{2+}$ currents elicited with pulses to $0 \mathrm{mV}$ are inhibited by $53.8 \pm 11 \%(n=9)$ in response to $30 \mathrm{nM} \mathrm{SS}$ and by $41.3 \pm 15.9 \%(n=5)$ with $10 \mu \mathrm{M}$ NE. In contrast, when the neurons are depolarized past the reversal potential to $+50 \mathrm{mV}$, the outward $\mathrm{Ca}^{2+}$ channel currents are little affected by either transmitter (Fig. 1). Thus, at $+100 \mathrm{mV}$, the mean inhibition seen with SS is only $7.3 \pm 2.4 \%$ $(n=4)$, whereas NE inhibits the current by only $4.6 \pm 1.1 \%(n$ $=5$ ). Thus, inhibition by both NE and SS is largely voltage dependent, similar to previous results in frog and rat sympathetic neurons.

As noted in previous studies, the inhibition by SS or NE of peak $\mathrm{Ca}^{2+}$ current is incomplete, even at negative potentials. To determine whether this partial inhibition is due to subsaturating transmitter concentrations, we obtained complete doseresponse curves for $\mathrm{Ca}^{2+}$ current inhibition by $\mathrm{SS}$ and $\mathrm{NE}$ at a test voltage of $0 \mathrm{mV}$. As shown in Figure 2, inhibition is incomplete even at saturating concentrations of the transmitters. The smooth curves were fitted to the dose-response data according to $I / I_{\max }=0.398+0.602 /\left(1+[\mathrm{SS}] / \mathrm{IC}_{50}\right)$, with $\mathrm{IC}_{50}=$ $7.3 \mathrm{nM}$, for SS (Fig. $2 A$ ) and $I / I_{\max }=0.569+0.43 /(1+[\mathrm{NE}] /$ $\mathrm{IC}_{50}$ ), with $\mathrm{IC}_{50}=1.6 \mu \mathrm{M}$, for $\mathrm{NE}$ (Fig. $2 B$ ). Thus, at saturating concentrations, SS inhibits about $60 \%$ of the $\mathrm{Ca}^{2+}$ current, whereas NE inhibits about $40 \%$ of the $\mathrm{Ca}^{2+}$ current.

A major goal of this study was to investigate the biochemical and kinetic mechanisms underlying the voltage-dependent inhibition. Toward this end we first considered the possible role of G-proteins and second messengers. Next we have investigated two alternate kinetic models for voltage-dependent $\mathrm{Ca}^{2+}$ channel inhibition. Finally, we consider possible interactions be- 


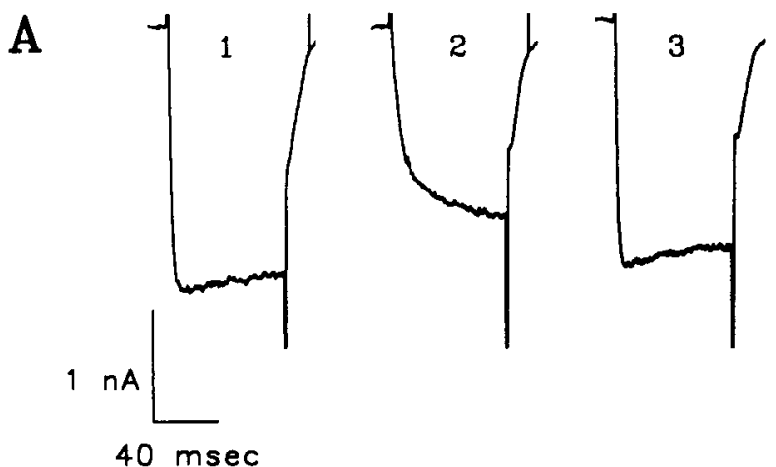

SS

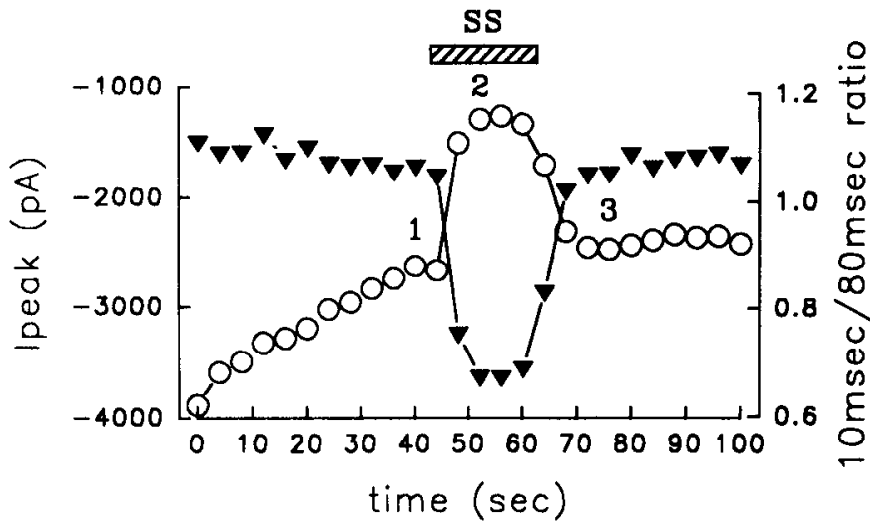

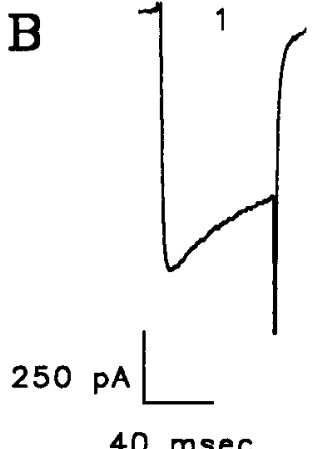
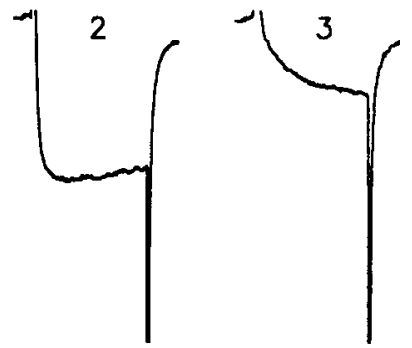

$40 \mathrm{msec}$

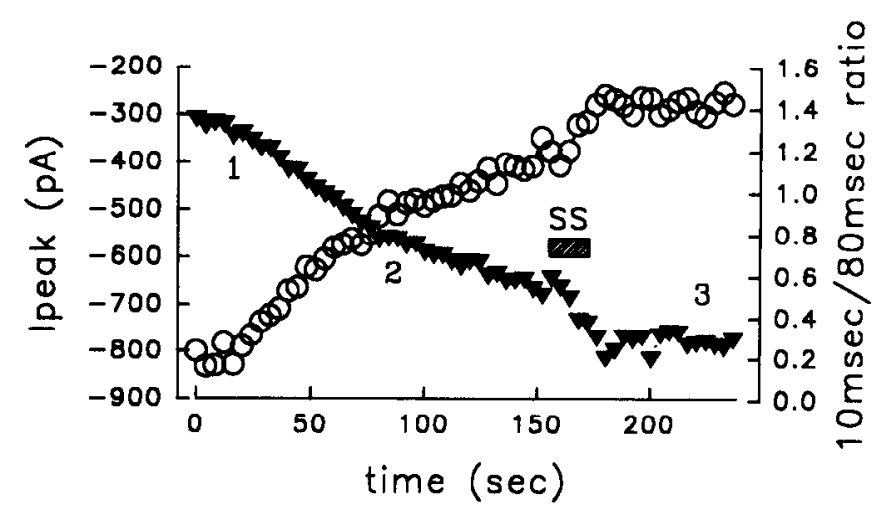

Figure 3. Effects of GTP- $\gamma-\mathrm{S}$ and SS on the kinetics of the Ca ${ }^{2+}$ current. $A$, Recordings from a cell dialyzed with $200 \mu \mathrm{M}$ GTP in pipette solution show the typical reversible slowing of the kinetics of the current. From a holding potential of $-80 \mathrm{mV}, 80 \mathrm{msec}$ pulses to $0 \mathrm{mV}$ were applied with a pulse interval of $10 \mathrm{sec}$. The top panel shows representative current traces taken at times indicated in the bottom panel, which plots peak inward current (circles) and ratio of current measured $10 \mathrm{msec}$ after onset of depolarization divided by the current at the end of the pulse (80 msec; triangles). Bar indicates period of application of SS. Note progressive rundown of $\mathrm{Ca}^{2+}$ current before application of SS with no change in $10 \mathrm{msec}$ : $80 \mathrm{msec}$ current ratio. $B$, Recordings from a cell dialyzed with a pipette solution containing GTP- $\gamma$-S (400 $\mu \mathrm{M}$ ) and no GTP. Note progressive slowing of current associated with inhibition of peak calcium current. Application of SS causes further rapid irreversible slowing of kinetics.

tween NE and SS and whether or not they target distinct populations of $\mathrm{Ca}^{2+}$ channels.

\section{Slowing of activation kinetics}

Calcium current inhibition with SS was also associated with a marked slowing in activation kinetics (Fig. 3A). This effect allowed us to distinguish clearly between transmitter-induced modulation of the calcium current and rundown associated with the whole-cell recording. As a convenient assay of channel kinetics, we plotted the ratio of the calcium current at $10 \mathrm{msec}$ following a step depolarization to $0 \mathrm{mV}$ (normally the time of peak inward current) to the current at $80 \mathrm{msec}$ (at the end of the pulse). As seen in Figure $3 A$, despite significant rundown in the calcium current following establishment of whole-cell recording, the calcium current ratio $(10 \mathrm{msec}: 80 \mathrm{msec})$ is relatively stable. Under control conditions, the value of the ratio is slightly greater than 1, reflecting a small amount of inactivation during the $80 \mathrm{msec}$ pulse. Upon application of SS, there is a reversible inhibition in peak $\mathrm{Ca}^{2+}$ current amplitude. Moreover, there is a dramatic and reversible decrease in the current ratio due to the slowing of activation.

\section{Role of $G$-proteins and second messengers}

Pretreatment of the sympathetic neurons with PTX overnight (200 $\mathrm{ng} / \mathrm{ml}$ ) completely abolished the response to both NE and SS, suggesting that both inhibitory transmitter actions are mediated by PTX-sensitive G-proteins (data not shown; $n=7$ ).

A role for $\mathrm{G}$-proteins was also suggested by experiments where GTP- $\gamma-\mathrm{S}(400 \mu \mathrm{M})$ was included in the pipette solution to ac- tivate G-proteins. Under these conditions, the calcium current was rapidly inhibited upon establishment of whole-cell recording, presumably due to the activation of G-proteins (Fig. 3B). This inhibition can be distinguished from normal rundown because it was associated with a marked slowing of the activation kinetics of the $\mathrm{Ca}^{2+}$ current, as evidenced by the progressive decrease in the $10 \mathrm{msec}: 80 \mathrm{msec}$ current ratio. Application of SS $(1 \mu \mathrm{M})$ during dialysis with GTP- $\gamma-S$ produced a further irreversible reduction of the current.

We examined two possible second messenger cascades as potential mediators of the inhibitory responses. Arachidonic acid (AA) had variable effects on the calcium current. At concentrations above $10 \mu \mathrm{M}$, AA did cause some inhibition of the $\mathrm{Ca}^{2+}$ current (Bug et al., 1989). However, this inhibition involved a simple scaling of the $\mathrm{Ca}^{2+}$ current amplitude with no change in channel kinetics and so did not mimic the response to the transmitters. Inhibitors of the AA cascade, including nordihydroguaiaretic acid (NDGA) ( $3 \mu \mathrm{M}, n=4)$, baicalein ( $1 \mu \mathrm{M}, n=3)$, and indomethacin $(10 \mu \mathrm{M}, n=4)$, did not affect the response to the transmitters. We also tested the possible role of PKC using 1-3-min-long applications of the PKC activators dioleylglycerol (50 $\mu \mathbf{M}, n=3$ ), octylindolactam (100 nм, $n-3$ ), or phorbol 12,13-diacetate (1 $\mu \mathrm{M}, n=4)$. None of these agents affected the calcium current.

\section{Unblock and reblock kinetics}

The above results indicate that the $\mathrm{Ca}^{2+}$ current inhibition we observe in the chick sympathetic neurons is similar to the G-pro- 
Figure 4. Time and voltage dependence of removal of inhibition. $A$, Effect of changing prepulse potential. $A 1$ shows individual current traces (bottom traces) and voltage protocol (top trace) as prepulse voltage was varied from -80 to $+120 \mathrm{mV}$. A2, Plot of effect of prepulse voltage on peak current amplitude. Peak current during second test voltage step $\left(V_{2}\right)$ divided by peak current during first test voltage step $\left(V_{1}\right)$ and then multiplied by $100 \%$. The cells were loaded with 1 mM GTP- $\gamma-S$ and then briefiy exposed to $30 \mathrm{nM}$ SS to achieve maximal activation of G-proteins. The smooth curve was drawn with the equation $I_{1} / I_{2}=\left(1-N_{1}\right) /(1+$ $\left.\exp \left(\left(V_{\text {pre }}-V_{1 / 2}\right) / k\right)\right)+N_{1}$, where $I_{1}$ and $I_{2}$ are the peak inward currents elicited by the first and second pulses, respectively, $V_{\text {pre }}$ is the prepulse potential, $V_{1 / 2}$ is the potential of this pulse for half removal of inhibition, and $k$ is the slope factor for voltage dependence. $N_{1}=0.49$; $V_{1 / 2}=17.84 ; k=13.97$. B. Time dependence of unblock. $B I$ shows voltage protocol (top trace) and individual current records (bottom traces). Duration of prepulse (to $+100 \mathrm{mV}$ ) varied from 1 to $15 \mathrm{msec}$. $B 2$, Plot of enhancement of current during second test pulse $\left(I_{2}\right)$ as function of prepulse duration. The data were fit using the equation $\left(I_{2} / I_{1}\right)$ - $100 \%=a+b *(1-\exp (-t / \tau))$, where $a-95.5, b-104.5$, and $\tau-6.1 \mathrm{msec}$.

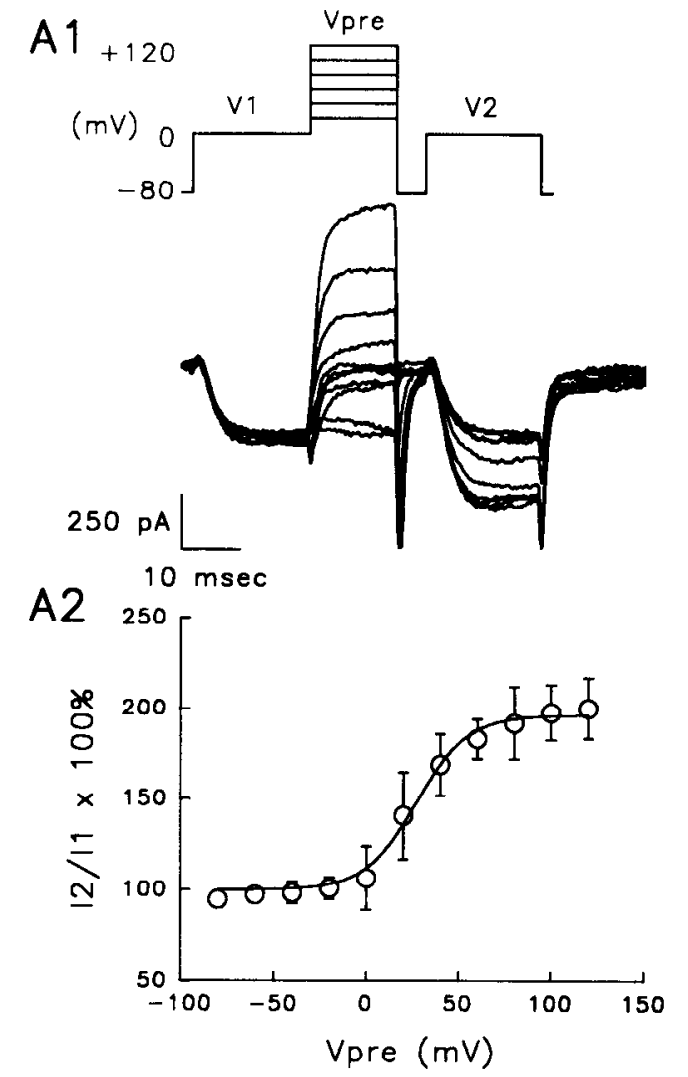

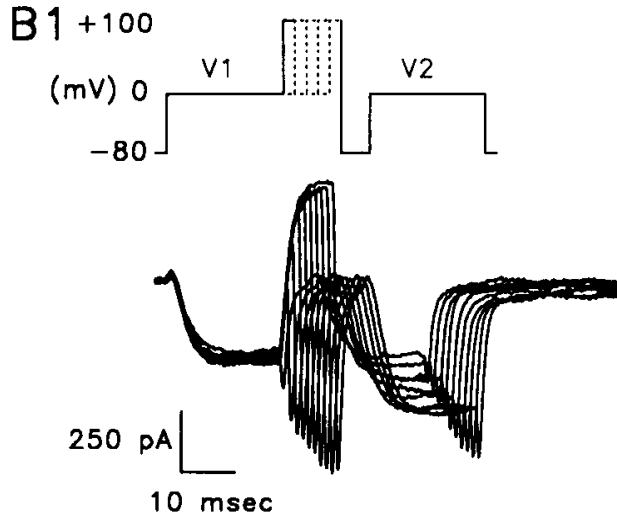

B2

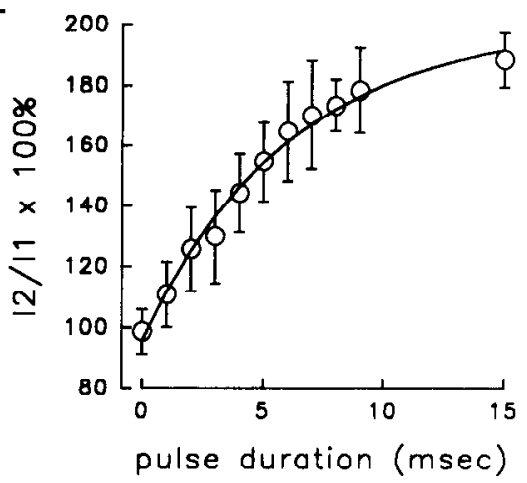

tein-mediated voltage-dependent inhibition previously described in other systems (e.g., Dolphin, 1991). We therefore next investigated the kinetic basis for this inhibition. Does it reflect the state-dependent binding and unbinding of an inhibitory molecule, perhaps the G-protein itself, or does it reflect a novel voltage-dependent gating step inherent to the modulated channel? We have approached this problem by measuring the kinetics of channel reblock at $-80 \mathrm{mV}$ following a strong depolarizing prepulse.

To study the reblock kinetics in the presence of transmitters, we needed to define a pulse protocol sufficient to unblock the inhibited current maximally. We first measured the voltage dependence of unblock in cells where the current was maximally inhibited (i.c., after SS application to a cell dialyzed with $1 \mathrm{~mm}$ GTP- $\gamma$-S). The voltage protocol was similar to that of Elmslie et al. (1990). It consisted of an initial $20 \mathrm{msec}$ test pulse to 0 $\mathrm{mV}\left(V_{1}\right)$ following a $4 \mathrm{sec}$ rest period at $-80 \mathrm{mV}$. The $\mathrm{Ca}^{2+}$ current during this first test pulse $\left(I_{1}\right)$ provides an assay of the extent of $\mathrm{Ca}^{2+}$ current inhibition at the resting potential (Fig. $4 A$ ). This pulse was immediately followed by a $15 \mathrm{msec}$ conditioning prepulse to various potentials ( $\left.V_{\text {pre }}\right)$ to relieve inhibition. The cell was then repolarized to $-80 \mathrm{mV}$ for $5 \mathrm{msec}$ to close channels that were activated by the $15 \mathrm{msec}$ pulse. A second $20 \mathrm{msec}$ test pulse to $0 \mathrm{mV}\left(V_{2}\right)$ was then applied to assay the effect of the interposed prepulse. Under control conditions (i.e., in the absence of transmitter or GTP- $\gamma-S$ ), the prepulse normally recruits no extra $\mathrm{Ca}^{2+}$ current (e.g., Fig. 6, top). However, under modulating conditions, the $\mathrm{Ca}^{2+}$ current during the second test pulse shows a clear increase with increasingly depolarized prepulse potentials (Fig. 4Al). The ratio of the peak current during the second test pulse to the peak current during the first test pulse $\left(I_{2}: I_{1}\right)$ was plotted as a function of the prepulse voltage (Fig. 4A2). The current ratio increases with an S-shaped dependence on prepulse potential, reaching a maximal enhancement with pulses positive to $+75 \mathrm{mV}$, with half-maximal activation occurring at $+18 \mathrm{mV}$.

To determine the time course of unblock during the prepulse depolarization, we varied the duration of the prepulse at a fixed potential of $+100 \mathrm{mV}$ (Fig. $4 B$ ). The ratio $I_{2}: I_{1}$ increases along an exponential time course with a time constant $(\tau)$ of $6.1 \mathrm{msec}$. From the time course and voltage dependence of unblock, we estimate that a $15 \mathrm{msec}$ prepulse to $+100 \mathrm{mV}$ should produce $91 \%$ of maximal unblock.

\section{Do reblock kinetics vary with the level of inhibition?}

Perhaps the most direct approach to address this question is to measure reblock kinetics at different concentrations of transmitter. However, the inhibitory responses to SS or NE both exhibit significant desensitization, either to a single prolonged application of transmitter or to multiple brief applications of transmitter (Fig. 5). Although such desensitization prevents us from comparing reblock kinetics at different transmitter concentrations, it does permit an alternate approach of measuring reblock kinetics at different times during a single prolonged application of transmitter, when the extent of inhibition is declining due to desensitization. This approach assumes that desensitization occurs at a step that is proximal to the activation of the inhibitory particle such that the extent of desensitization reflects the decrease in active inhibitory molecules. An alternate interpretation is that desensitization is downstream of the inhibitory molecule, perhaps at the level of the Ca channel-inhibitory particle interaction. However, this latter possibility seems 


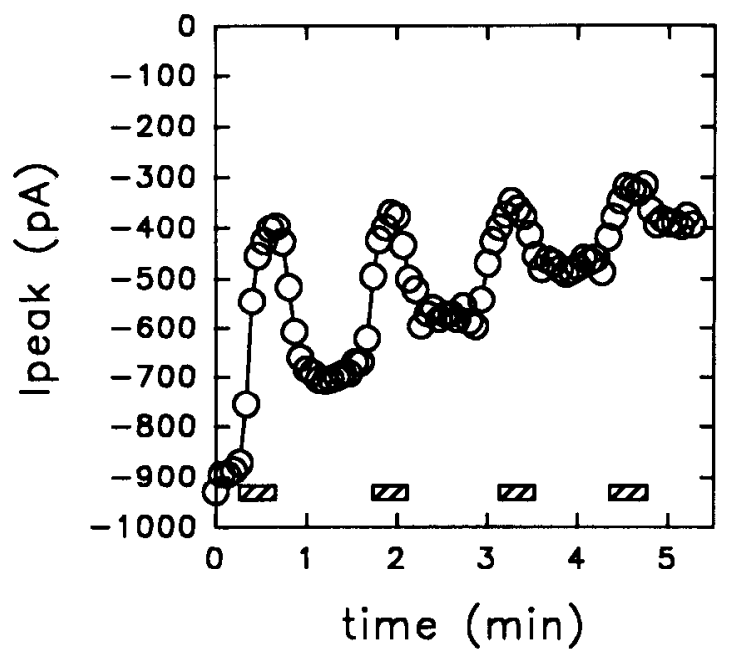

Figure 5. Desensitization of the response to SS. Successive applications of SS ( $30 \mathrm{nM}$; indicated by bars) elicited progressively smaller inhibitory responses of peak calcium current $\left(I_{\text {peak }}\right)$. The cell was held at $-80 \mathrm{mV}$ and stepped to $0 \mathrm{mV}$ for $20 \mathrm{msec}$ to elicit $\mathrm{Ca}^{2+}$ current. The inhibition was then relieved by a $15 \mathrm{msec}$ pulse to $+100 \mathrm{mV}$, and the response to a second $20 \mathrm{msec}$ pulse to $0 \mathrm{mV}$ measured. The peak current in response to the first pulse to $0 \mathrm{mV}$ is plotted.

unlikely for several reasons. First, desensitization has been shown to occur at the receptor levels in a wide variety of systems (Huganir and Greengard, 1990). Second, activation of G-proteins by SS in the presence of GTP- $\gamma$-S resulted in a maintained inhibition with no sign of desensitization (A. Golard and S. A. Siegelbaum, unpublished observations). Third, in cross-desensitization experiments with SS and NE, prolonged application of SS did not appear to alter the response to NE (see Fig. 8 and below). We will thus assume that desensitization reflects a decreased level of $\mathrm{G}$-protein activation leading to a reduced concentration of active inhibitory molecules.

The effects of desensitization on reblock kinctics arc illustrated in Figure 6, which shows an experiment where reblock kinetics were assayed every $30 \mathrm{sec}$ during a continuous $3.5 \mathrm{~min}$ application of SS. After $2 \mathrm{~min}$ in the presence of SS, a solution containing saturating concentrations of both SS and NE was applied for the remaining $1.5 \mathrm{~min}$. Reblock kinetics were measured using a voltage-clamp protocol illustrated at the top of Figure 6. Calcium current was first elicited with a lest pulse to $0 \mathrm{mV}$ for $20 \mathrm{msec}$ from a holding potential of $-80 \mathrm{mV}\left(V_{1}\right)$. The membrane was then stepped to $+100 \mathrm{mV}$ for $15 \mathrm{msec}$, which should allow for nearly complete unblock as defined by the experiments of Figure 4 . The membrane was then repolarized to $-80 \mathrm{mV}$ for a variable time and the extent of reblock assayed by a second test pulse to $0 \mathrm{mV}\left(V_{2}\right)$.

The top current records in Figure 6 show that in the absence of transmitter, the magnitude of the calcium current is stable and not altered by the prepulsc protocol. In contrast, the second set of current records show that immediately after application of SS, at a time when there is no desensitization and inhibition of the calcium current is maximal, the prepulse causes a significant enhancement in the calcium current during the second test pulse. When the second pulse is applied after only a brief period of repolarization to $-80 \mathrm{mV}$, the extent of enhancement is greatest. However, as the period of repolarization is prolonged, the calcium current elicited during the second test pulse
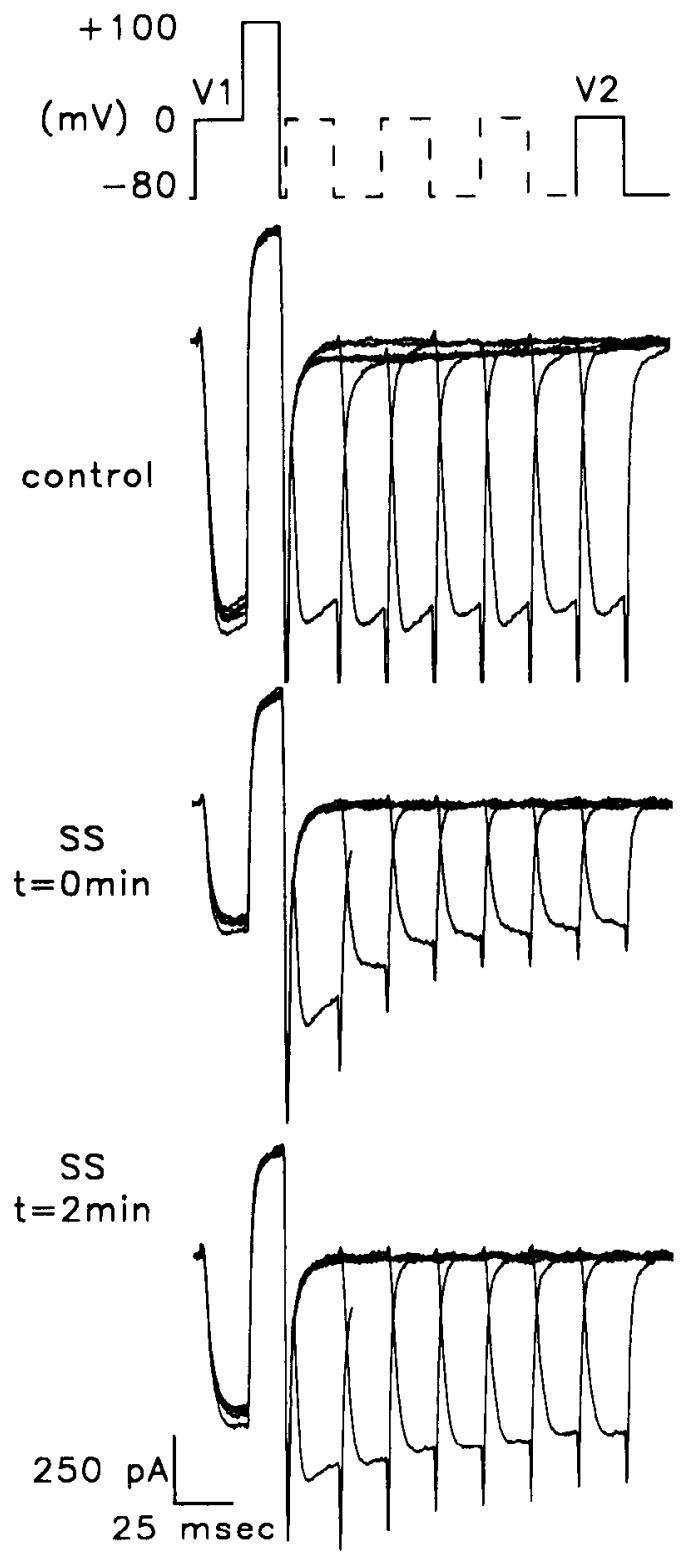

Figure 6. Desensitization alters the kinetics of reblock. Top trace shows voltage protocol used to assay reblock kinetics. Each record consists of a test pulse to $0 \mathrm{mV}\left(V_{1}\right)$ followed by a depolarizing prepulse to +100 $\mathrm{mV}$, followed by a variable interval at $-80 \mathrm{mV}$, followed by a second test pulse $\left(V_{2}\right)$. The interval at $-80 \mathrm{mV}$ was varied from $2.6 \mathrm{msec}$ to $122.6 \mathrm{msec}$ in $20 \mathrm{msec}$ increments (total of seven records). Each set of pulses (i.e., one record) was given at $2 \mathrm{sec}$ intervals. The entire series of seven records was repeated once every $30 \mathrm{sec}$. The control traces illustrate current records in absence of transmitter. Note that prepulse has no effect on current in second test pulse. The middle set of current records (SS, $t=0 \mathrm{~min}$ ) was obtained within $20 \mathrm{sec}$ of first applying 30 nM SS, a time at which the inhibitory response was maximal. Bottom set of current records was obtained after $2 \mathrm{~min}$ in the continuous presence of SS, at a time when there was substantial desensitization. The pipette contained $200 \mu \mathrm{M}$ GTP.

becomes reinhibited and approaches its initial value evoked by the first test pulse.

As the duration of the SS application increases, there is a progressive desensitization in the response. Thus, after $2 \mathrm{~min}$ application of SS, the peak calcium current amplitude during the first test pulse has partly recovered back to its initial control level (e.g., compare current records in Fig. 6; see also Fig. 8, 

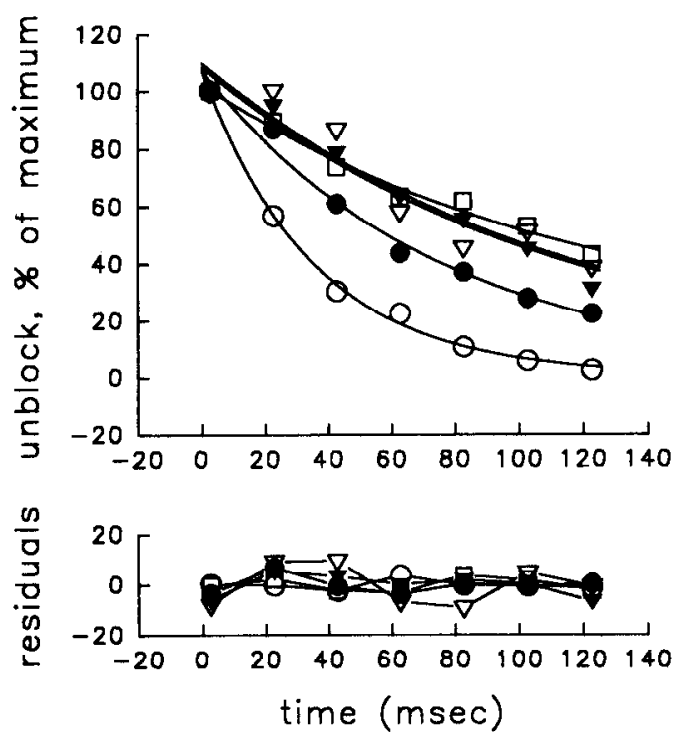

Figure 7. Exponential fits of time course of reblock during desensitization. Peak calcium currents were measured during the second test pulse $\left(V_{2}\right)$ using protocol illustrated in Figure 6 . The percentage unblock was measured as $\left(I_{2}-I_{1}\right) / I_{2} \times 100 \%$ for each repolarization interval and then normalized by percentage unblock measured after briefest interval (i.e., $2.6 \mathrm{msec}$ ). Reblock kinetics were fitted by a single exponential function: $y=a+b \exp (-t / \tau)$. Each symbol from a set of data obtained after a different length of time in presence of SS. Open circles, $20 \mathrm{sec}$ after application of SS; solid circles, $30 \mathrm{sec}$ after the first series; open triangles, $1 \mathrm{~min}$; solid triangles, $90 \mathrm{sec}$; squares, $2 \mathrm{~min}$. Bottom panel shows residuals of exponential fits. Lack of any clear trend indicates that single exponential fit provides a reasonable approximation to data.

top). Moreover, the percentage increase in calcium current during the second test pulse relative to the $\mathrm{Ca}^{2+}$ current during the first test pulse is reduced (due to the lesser degree of inhibition during the first test pulse). Importantly, there also appears to be a significant slowing in the rate at which the calcium current reblocks at $-80 \mathrm{mV}$.

To measure reblock kinetics quantitatively, we plotted the percentage unblock of the calcium current during the second test pulse (normalized to the maximal amount of unblock seen following the briefest repolarization to $-80 \mathrm{mV}$ ) as a function of the repolarization time at $-80 \mathrm{mV}$ (Fig. 7). The data clearly show that as desensitization proceeds, there is a steady decrease in the rate of reblock. The data were fitted rcasonably wcll by single exponential functions, providing values for the time constant of reblock that vary from $36 \mathrm{msec}$ at the earliest time in SS to a value of $126 \mathrm{msec}$ after $2 \mathrm{~min}$, when there was substantial desensitization.

In Figure 8 we plot peak calcium current amplitude at $0 \mathrm{mV}$ during the first test pulse, time constant of reblock, and maximum percentage unblock at different times during the prolonged application of SS. As the response desensitizes, there is a progressive increase in calcium current amplitude (top panel) and a progressive increase in the time constant of reblock (middle panel). Since measurements of peak calcium current are complicated by rundown, which will cause us to underestimate the extent of desensitization, we evaluated the extent of calcium current inhibition by measuring the maximal unblock produced by the large prepulse when the second test pulse is delivered after the shortest $(2.6-5.0 \mathrm{msec})$ repolarization interval. As shown by the middle panel of Figure 8 , the percentage unblock de-

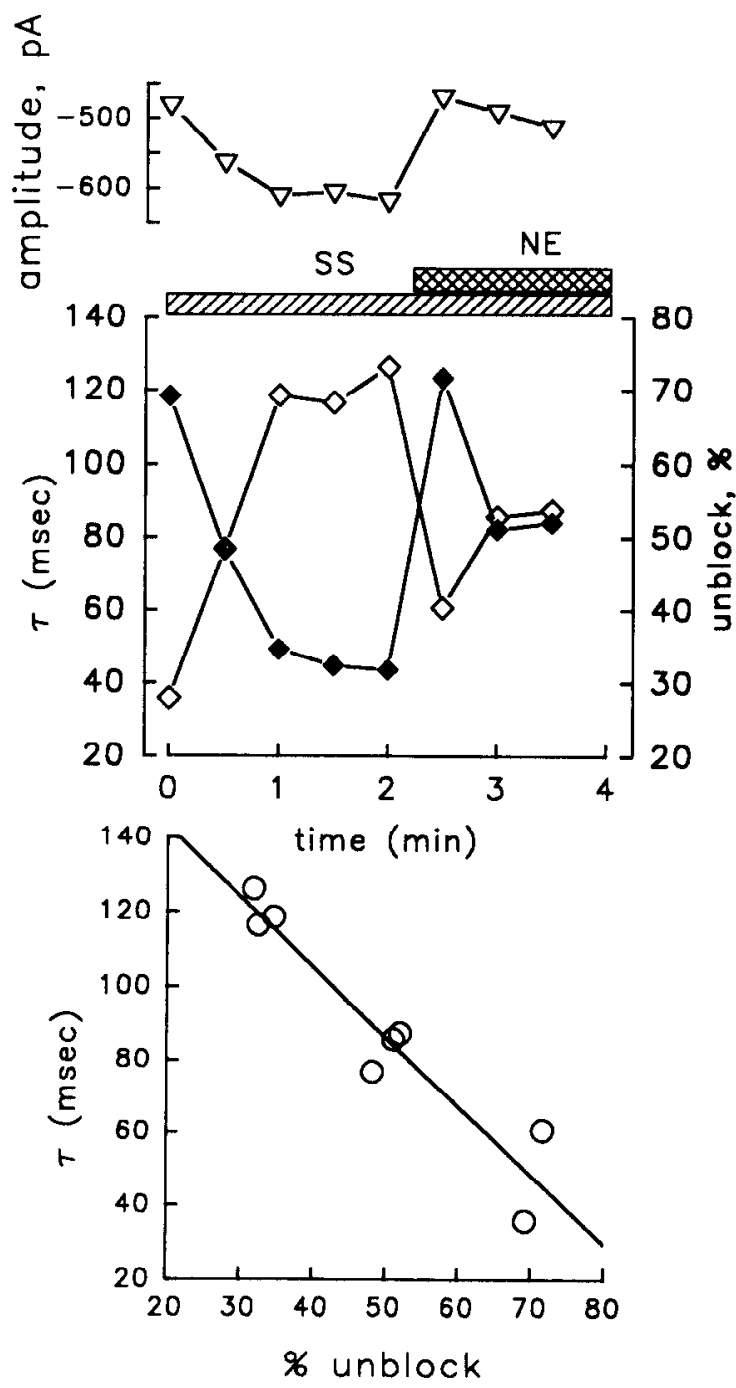

Figure 8. Correlation of changes in extent of inhibition with reblock kinetics during desensitization. Top panel plots peak calcium current during experiment. Time 0 corresponds to $20 \mathrm{sec}$ after start of application of SS. Bars indicate period of SS $(30 \mathrm{nM})$ and NE $(30 \mu \mathrm{M})$ application. Middle panel plots time constant of unblock (open symbols) obtained as in Figure 7 and percentage unblock during experiment (solid symbols). Percentage unblock was measured as $\left(I_{2}-I_{1}\right) / I_{1} \times 100 \%$ using shortest repolarization interval. Bottom panel plots time constant of unblock versus \% unblock. Line fit by a linear regression.

creases as the response to SS desensitizes. In the bottom panel of Figure 8, we show that during desensitization the slowing of reblock kinetics and the decrease in the amount of unblock are significantly correlated. Thus, these data provide strong qualitative evidence that reblock kinetics vary significantly as a function of the degree of channel inhibition and are thus consistent with the model of Bean (1989). Below we consider this question more rigorously by fitting a quantitative model to the data.

\section{Interactions between NE and SS}

As shown above, even at saturating concentrations of transmitter, the inhibition produced by NE or SS was incomplete. This result could be explained if NE and SS target distinct populations of $\mathrm{Ca}^{2+}$ channels. If this is indeed the case, we would predict that the inhibitory effects of NE and SS should be additivc. To test this possibility, we compared the effects of applying NE or SS alone with their combined action (all applied 
at maximally effective concentrations). As shown by the experiment of Figure $9 A$, the inhibition seen with the two transmitters was not additive. Thus, an initial application of SS alone inhibited the $\mathrm{Ca}^{2+}$ current by $51 \%$ while $\mathrm{NE}$ alone inhibited the current by $31 \%$. When NE and SS were then applied together, the $\mathrm{Ca}^{2}$ c current was inhibited by $41 \%$, which was less than the inhibition seen with SS alone.

One potential problem with this protocol is that the combined response to $\mathrm{NE}+\mathrm{SS}$ will be reduced due to the desensitization in response to the prior transmitter applications. We have tried to correct for such desensitization by bracketing the combined response to $\mathrm{NE}+\mathrm{SS}$ with prior and subsequent applications of $\mathrm{SS}$ and NE alone (Fig. 9A). We then compare the combined response to $\mathrm{NE}+\mathrm{SS}$ with averages of the bracketing responses to NE and SS alone. Using this approach, we found that SS alone inhibits the $\mathrm{Ca}^{2+}$ current by $39 \%$ while $\mathrm{NE}$ alone inhibits the $\mathrm{Ca}^{2+}$ current by $27.5 \%$. Thus, even after correcting for desensitization, the response to the combined application of NE + SS $(41 \%)$ clearly indicates that the two transmitter responses were not additive. Moreover, the response to the combined application of both transmitters was not significantly greater than the inhibition seen with SS alone.

As an independent approach to comparing the effects of combined and single applications of transmitter without complications from desensitization, we performed a set of experiments in which different cells were subjected to either a single application of NE, a single application of SS, or a single application of NE $+\mathrm{SS}$. The results of these experiments are shown in the bar graph (Fig. 9B). Again, it is clear that the response to the transmitters applied in conjunction is not larger than the response to SS alone. These results thus indicate that the two transmitters modulate the same population of $\mathrm{Ca}^{2+}$ channels.

Do the transmitters also recruit the same population of inhibitory molecules that are proposed to interact with the channel? One way of approaching this question is to compare the kinetics of reblock during an application of a saturating concentration of SS with reblock kinetics during the combined application of NE + SS. If the transmitters act through the same population of inhibitory molecules, we would predict that the rate of reblock with $\mathrm{NE}+\mathrm{SS}$ should equal the rate of reblock with SS alone. However, if the transmitters act through distinct molecules, then the rate of reblock should be greater with NE + SS due to the greater total concentration of activated inhibitory molecules compared to the rate of reblock with SS alone. In Figure $9 B$ we have compared the rates of reblock with $\mathrm{NE}$ alone, SS alone, and combined applications of SS + NE. The data show that the rate of reblock with SS alone is virtually identical to that seen with SS + NE. This then indicates that SS and NE activate the same population of inhibitory molecules, in addition to the same population of channels.

A potential trivial, although unlikely, explanation for the above findings is that NE and SS act through the same population of receptors. However, this possibility can be ruled out by crossdesensitization experiments. Figure 8 shows an experiment where NE was applied during a prolonged application of SS at a time when the response to SS had largely desensitized. Despite this desensitization to SS, NE was still able to inhibit the $\mathrm{Ca}^{2+}$ current to a normal extent.

\section{Kinetic model for channel inhibition}

To obtain a more quantitative estimate for how the rates of block and unblock vary with extent of inhibition and voltage,
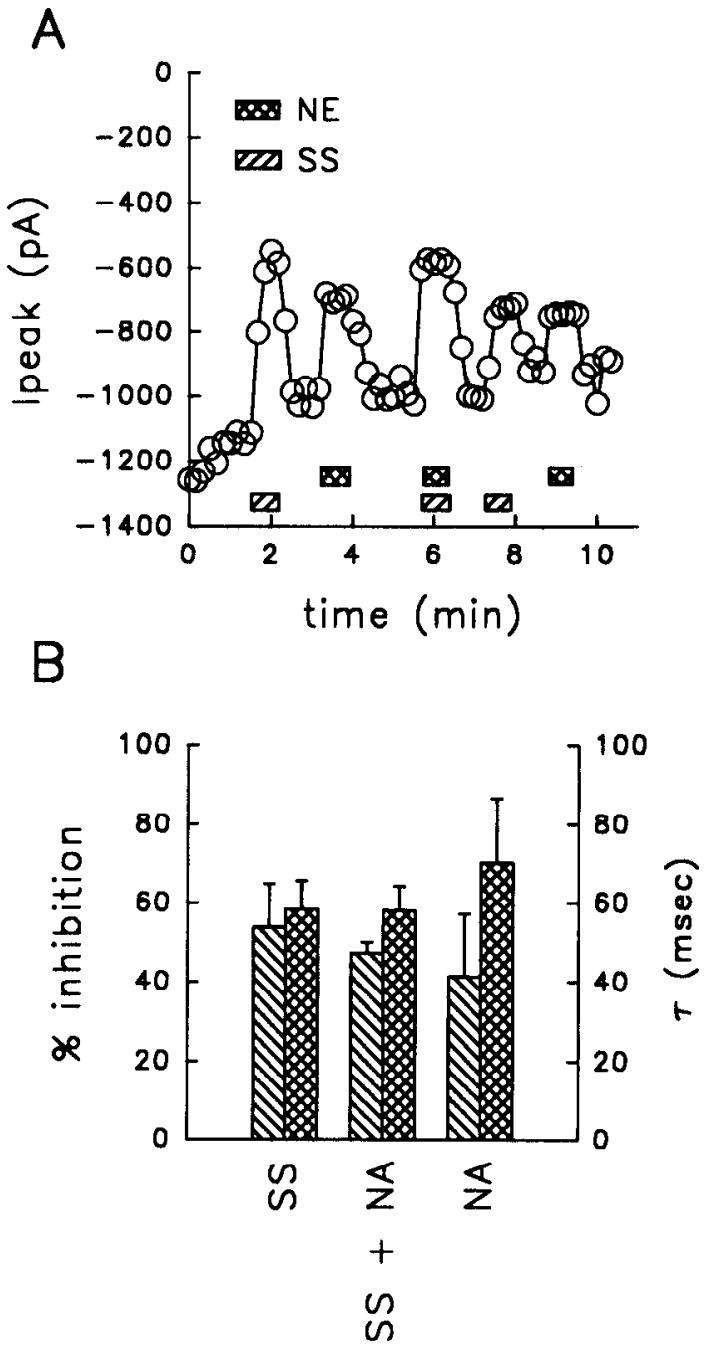

Figure 9. The effects of NE and SS are not additive. $A$, Effect of short $(20 \mathrm{sec})$ repeated applications of SS $(30 \mathrm{nM})$ or NE $(30 \mu \mathrm{M})$ on $\mathrm{Ca}^{2}+$ current measured with $50 \mathrm{msec}$ pulses to $0 \mathrm{mV}$ from a holding potential of $-80 \mathrm{mV}$ (delivered at $0.1 \mathrm{~Hz}$ ). $\mathrm{Ca}^{2+}$ current was measured $7 \mathrm{msec}$ after the start of the pulse. The drugs were applied by local superfusion. $B$, Summary of interaction experiments. Hatched bars show percentage inhibition of $\mathrm{Ca}^{2+}$ current measured at $7 \mathrm{msec}$. Crosshatched bars show time constant of reblock at $-80 \mathrm{mV}$ (measured as in Fig. 6). Bars represent mean $\pm \mathrm{SD}$, obtained from the first response of a cell to a transmitter or combination of transmitters. The concentrations used were SS, $30 \mathrm{nM}$, and NE, $30 \mu \mathrm{M} ; n=8,3$, and 5 for SS, SS + NE, and $\mathrm{NE}$, respectively.

we fitted $\mathrm{Ca}^{2+}$ currents measured during the reblock protocol (e.g., Fig. 6) with a kinetic model extended from that of Bean (1989) and Elmslie et al. (1990). We first used a Hodgkin-Huxley model for channel activation incorporating $\mathrm{m}^{2}$ kinetics (i.e., two closed states leading to an open state). Inactivation proceeds only from the open state and was assumed to be complete during the test depolarizations to $0 \mathrm{mV}$. Control $\mathrm{Ca}^{2+}$ currents (measured in the absence of transmitter) were first fit with this gating scheme to derive rate constants for activation and inactivation of the willing channel (top row in Fig. 10A). The values for these rate constants were then fixed during subsequent fits of the model to the $\mathrm{Ca}^{2+}$ currents obtained in the presence of transmitter.

In the reaction scheme of Figure $10 \mathrm{~A}$, transitions between willing and reluctant modes are represented by the vertical reaction steps. We assume that channels in either closed states or 


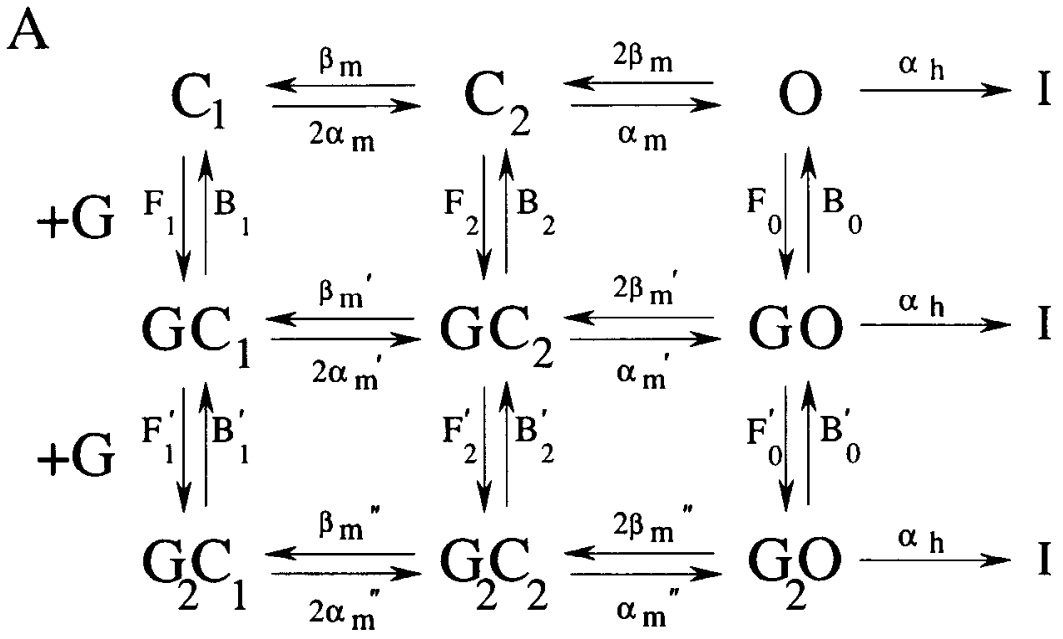

Figure 10. Kinetic modeling of calcium channel modulation. $A$, Kinetic scheme for modulation. Top row shows normal Hodgkin-Huxley activation with inactivation from open state for willing channels. Middle and bottom rows represent channels in reluctant modes. Channels enter the first reluctant mode (middle row) from willing state by binding an inhibitory molecule $(G)$. Channels enter the second reluctant mode by binding a second inhibitory molecule. Channels leave reluctant modes when $\mathrm{G}$ dissociates. $B$, Fits of model shown in $A$ to data of Figure 6 . Nonlinear least-squares simplex routine used to fit data. Smooth curves are fits of model, noisier traces show experimental data. Traces in panel on left were obtained at peak of SS inhibition $(t=0 \mathrm{~min})$. Data on right obtained after substantial desensitization $(t=2 \mathrm{~min}$ in SS). Throughout most of the time course of the currents, data are well fitted by model. Similarly good fits were obtained for intermediate times during SS application.
B
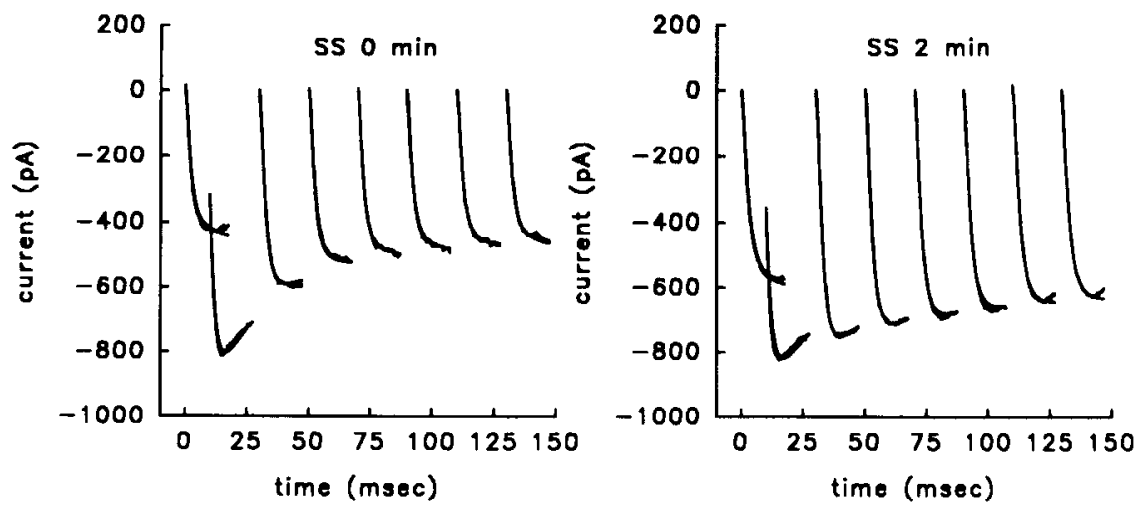

open states can undergo transitions between willing and reluctant modes of gating; however, the rates of interconversion arc different from different states. To simplify the scheme, we assume that the interconversion rates between the intermediate closed states $\left(\mathrm{C}_{2}\right)$ are the geometric mean of the rates between open states $(\mathrm{O})$ and the fully closed state $\left(\mathrm{C}_{1}\right)$. Channels in the reluctant mode have altered rates for channel activation $\left(\alpha_{\mathrm{m}}\right.$ and $\beta_{\mathrm{m}}$ ) but we assume that the rate of inactivation from the open state $\left(\alpha_{\mathrm{h}}\right)$ is constant. We also assume that while the rates of activation are voltage dependent, the rates of interconversion between willing and reluctant modes ( $\mathrm{F}$ and $\mathrm{B})$ are voltage independent.

\section{Table 1. Rate constants for the transitions between willing and} reluctant modes

\begin{tabular}{llllll} 
Time & \% Unblock & $\mathrm{F}_{1}$ & $\mathrm{~F}_{1}{ }^{\prime}$ & $\mathrm{B}_{1}$ & $\mathrm{~B}_{1}{ }^{\prime}$ \\
\hline $0 \mathrm{~min}$ & 69.2 & 50.3 & 3.1 & 11.8 & 10.3 \\
$0.5 \mathrm{~min}$ & 48.3 & 20.4 & 1.8 & 12 & 6.4 \\
$1 \mathrm{~min}$ & 34.6 & 15.8 & 1.8 & 8.1 & 9.2 \\
$1.5 \mathrm{~min}$ & 32.4 & 10.1 & 1.2 & 7.5 & 7.2 \\
$2 \mathrm{~min}$ & 31.8 & 11 & 1.3 & 10.2 & 3.6
\end{tabular}

The model in Figure $10 \mathrm{~A}$ was used to fit the data shown in Figures 6-8. The rate constants $\left(\mathrm{sec}^{-1}\right)$ obtained at different times during continuous application of SS are shown. Time zero data were obtained at peak of SS response.
To model reblock kinetics using the protocol shown in Figure 6 , we assumed that (1) immediately following the prepulse to $+100 \mathrm{mV}, 91 \%$ of the channels are in the willing state, based on the data of Figure 5 ; (2) during the period at $-80 \mathrm{mV}$, channels re-equilibrate between willing and reluctant modes through transitions among the fully closed states (e.g., $\mathrm{C}_{1}, \mathrm{GC}_{1}$, $\mathrm{G}_{2} \mathrm{C}_{1}$ ); and (3) finally, the rate constants obey microscopic reversibility.

We first tried fitting our data with only a single reluctant mode of gating, similar to the approach of Elmslie et al. (1990). While this provided a reasonably good fit to the data, the derived values for the rate constant $B_{1}$ [i.e., the rate constant for transitions from the fully closed reluctant state $\left(\mathrm{GC}_{1}\right)$ to the fully closed willing state $\left(C_{1}\right)$ ] showed a threefold decrease as desensitization occurred. However, according to our physical interpretation, this rate constant reflects the unbinding of an inhibitory molecule from the channel. Therefore, $B_{1}$ should be independent of the concentration of activated inhibitory molecule, and thus should be independent of the extent of inhibition or desensitization. In contrast, the forward rate for conversion from the willing to the reluctant mode $\left(F_{1}\right)$ is expected to increase with increasing inhibition, as it should be a first-order process depending on the concentration of activated inhibitory molecules.

We therefore tested a more complicated model in which there were two reluctant modes of gating (mode 1 and mode 2) corresponding to channels with one or two inhibitory molecules 
bound (e.g., see Boland and Bean, 1993). We first specified that the two binding events involved identical molecules interacting with identical, independent sites on the $\mathrm{Ca}^{2+}$ channel. However, this approach failed to provide a satisfactory fit to the data. In contrast, when we allowed the interconversion rates (as well as the modified rates of activation) to be unconstrained in the fit, we obtained quite good fits to the data throughout the entire time course of desensitization (Fig. $10 \mathrm{~B}$ ). Moreover, the derived rates for interconversion between the willing and first reluctant mode (one inhibitory molecule bound) were now consistent with our physical model. Thus, the rate constants for dissociation of the inhibitory molecule $\left(B_{1}\right)$ showed little dependence on the degree of desensitization while the forward rate constant for binding of inhibitory molecules $\left(\mathrm{F}_{1}\right)$ showed a progressive decline as the extent of inhibition decreased during desensitization (Table 1). However, the rate of dissociation of the second bound inhibitory molecule $\left(B_{1}{ }^{\prime}\right)$ still showed some decrease during desensitization. Possible reasons for this behavior are discussed below. The values for the other rate constants in the model governing the activation transitions of the reluctant modes and transitions between willing and reluctant open states showed a large variation among the different fits and were not well defined. This is not surprising since these rates actually play little part in determining the current during our short test pulses to $0 \mathrm{mV}$, as channels in reluctant modes show little activation during the short test pulses.

\section{Discussion}

The above results show that SS and NE produce a voltagedependent inhibition of the $\mathrm{Ca}^{2+}$ current in chick sympathetic neurons that is very similar to examples of $\mathrm{Ca}^{2+}$ channel modulation previously reported for frog and rat sympathetic neurons, chick and rat sensory neurons, and a variety of central neurons (Dolphin, 1991; Hille, 1992). Also in agreement with previous results, we find that $\mathrm{Ca}^{2+}$ channel inhibition depends on the activation of a PTX-sensitive G-protein and does not appear to be mediated by AA or PKC activation (Kasai and Aosaki, 1989; Bley and Tsien, 1990; Plummer et al., 1991).

Similar to results of Elmslie et al. (1990), we found that a strong depolarizing prepulse is able to relieve the inhibition transiently. After repolarizing the membrane to $-80 \mathrm{mV}$, the channel reblocks along an exponential time course with a time constant ranging from $50 \mathrm{msec}$ to $>100 \mathrm{msec}$. The voltage dependence of inhibition could result from a voltage-dependent binding and unbinding of the blocking particle or it could reflect voltage-independent binding reactions coupled to the voltage dependence of channel activation. Our results are consistent with models that attribute this unblock and reblock to the unbinding and binding of an inhibitory molecule, perhaps the G-protein itself, to the channel. Our modeling results are consistent with the view that the rates of conversion between willing and reluctant states are voltage independent. However, these rates do depend on the activation state of the channel.

Our results are thus in agreement with the model of Bean (1989) and the data of Lopez and Brown (1991) but do not support the alternate model of Kasai (1992). Kasai's model was based on the finding that the slow activation kinetics of calcium current during a moderate depolarization, presumably reflecting unblock, were independent of transmitter concentration. In support of Kasai's model, Elmslie and Jones (1992) report that the kinetics of reblock at $-10 \mathrm{mV}$ following a strong depolarizing prepulse also are independent of transmitter concentration. It is possible that these discrepancies could be due to differences in the actions of distinct transmitters. However, the slow $\mathrm{Ca}^{2+}$ current kinetics during a long depolarization are governed not only by the slow rates of transitions between willing and reluctant states, which depend on the concentration of inhibitory molecules, but also on the rapid rates of channel activation and inactivation gating, which are independent of inhibitory molecule concentration. In contrast, measuring the rate of reblock at $-80 \mathrm{mV}$ minimizes contributions from channel gating.

Fits of quantitative models to the reblock data yield further insight into the mechanism of modulation. Thus, more than one reluctant gating mode was required to achieve an adequate description of the data. This is in agreement with the singlechannel results of Delcour et al. (1993), who found three modulated gating modes based on measurements of single-channel open time and open probability. This also agrees with the results of Boland and Bean (1993), which required more than one G-protein-modulated state to account for the voltage dependence of calcium channel modulation. In modeling our data, we assumed that the two reluctant modes correspond to channels with either one or two bound inhibitory molecules. Since the calcium channel contains four pseudosubunits, the binding of more than one inhibitor to the channel does not seem unreasonable. If the binding sites for the two inhibitor molecules were identical and independent, we would predict from mass action that the forward rate for the first binding reaction should be twice that of the second binding reaction while the back rate for the second binding reaction should be twice that of the first binding reaction. In contrast, the rate constants derived from fits of the model suggest that the forward rate of the second step is about 10-fold slower than that of the first step, while the two unbinding rates are roughly equal. This could indicate that either the two sites are not functionally identical or that the binding of one inhibitor influences the binding of the second. Even with two reluctant modes, the rate of inhibitory molecule dissociation from the second reluctant state shows some dependence on the extent of desensitization. This might simply reflect uncertainties in fitting the relatively small contribution of the second reluctant mode or it might indicate the presence of additional reluctant modes corresponding to three or four bound inhibitory molecules (e.g., Boland and Bean, 1993).

Finally, our data also suggest that NE and SS inhibit the same population of calcium channels since the inhibition is not additive. Moreover, since the rate of reblock with the transmitters is also not additive, we propose that the two transmitters activate the same population of inhibitory molecules and that SS alone can maximally activate these molecules. It has been suggested that the inhibitory molecule is the activated G-protein. If this is the case, our data suggest that NE and SS interact with the same population of G-proteins. Alternatively, NE and SS could interact with separate G-proteins, which then interact with a common effector-the proposed inhibitory molecule. Although we have no data as to whether SS and NE interact with distinct or identical G-proteins in the chick sympathetic neurons, the experiments of Taussig et al. (1992) in hybrid ratmousc NG-108 ncuroblastoma cells suggest that these transmitters do interact with distinct $\mathrm{G}$-proteins to inhibit $\mathrm{Ca}^{2+}$ current. In the rat pituitary GH3 tumor cell line, SS and muscarinic receptor activation modulate dihydropyridine-sensitive calcium channels through two distinct subtypes of the PTX-sensitive $\mathrm{G}_{o}$-type protein (Kleuss et al., 1991). Experiments using antisense oligonucleotides to delete G-protein subtypes selectively 
in chick sympathetic neurons may help in distinguishing between these possibilities.

\section{References}

Bean BP (1989) Neurotransmitter inhibition of neuronal calcium currents by changes in channel voltage dependence. Nature 340:153156.

Beech DJ, Bernheim L, Hille B (1992) Pertussis toxin and voltage dependence distinguish multiple pathways modulating calcium channels of rat sympathetic neurons. Neuron 8:97-106.

Bley KR, Tsien RW (1990) Inhibition of $\mathrm{Ca}^{2+}$ and $\mathrm{K}^{+}$channel in sympathetic neurons by neuropeptides and other ganglionic transmitters. Neuron 2:379-391.

Boland LM, Bean BP (1993) Modulation of N-type calcium channels in bullfrog sympathetic neurons by luteinizing hormone-releasing hormone: kinetics and voltage dependence. J Neurosci 13:516-533.

Bug W, Role LW, Siegelbaum SA, Simmons L (1989) Arachidonic acid inhibits calcium current in chick sympathetic neurons. Soc Neurosci Abstr 15:177.

Delcour AH, Lipscombe D, Tsien RW (1993) Multiple modes of $\mathrm{N}$-type calcium channel activity distinguished by differences in gating kinetics. J Neurosci 13:181-194.

Doerner D, Pitler TA, Alger BE (1988) Protein kinase C activators block specific calcium and potassium current components in isolated hippocampal neurons. J Neurosci 8:4069-4078.

Dolphin AC (1991) Regulation of calcium channel activity by GTP binding proteins and second messengers. Biochim Biophys Acta 1091: 68-80.

Dolphin AC, Scott RH (1987) Calcium channel currents and their inhibition by $(-)$-baclofen in rat sensory neurones: modulation by guanine nucleotides. J Physiol (I ond) 386:1-17.

Dunlap K, Fischbach GD (1981) Neurotransmitters decrease the calcium conductance activated by depolarization of embryonic chick sensory neurones. J Physiol (Lond) 317:519-535.

Elmslie KS, Jones SW (1992) Concentration dependence of transmitter effects on calcium current kinetics in frog sympathetic neurons. Soc Neurosci Abstr 18:433.

Elmslie KS, Zhou W, Jones SW (1990) LHRH and GTP- $\gamma-S$ modify calcium current activation in bullfrog sympathetic neurons. Neuron 5:75-80.

Ewald DA, Sternweis PC, Miller RJ (1988) Guanine nucleotide-binding protein $\mathrm{G}_{o}$-induced coupling of neuropeptide $Y$ receptors to $\mathrm{Ca}^{2+}$ channels in sensory neurons. Proc Natl Acad Sci USA 85:3633-3637.

Forscher P, Oxford GS (1985) Modulation of calcium channels by norepinephrine in internally dialyzed avian sensory neurons. J Gen Physiol 85:743-763.

Forscher P, Oxford GS, Schulz D (1986) Noradrenaline modulates calcium channcls in avian dorsal root ganglion cclls through tight receptor-channel coupling. J Physiol (Lond) 379:131-144.

Hille B (1992) G protein coupled mechanisms and nervous signalling. Neuron 9:187-195.

Huganir RL, Greengard P (1990) Regulation of neurotransmitter re- ceptor desensitization by protein phosphorylation. Neuron 5:555567.

Ikeda SR, Schofield GG (1989) Somatostatin blocks a calcium current in rat sympathetic ganglion neurones. J Physiol (I ond) 409:221-240.

Jones SW, Marks TN (1989) Calcium currents in bullfrog sympathetic neurons I. Activation kinetics and pharmacology. J Gen Physiol 94: $151-167$.

Kasai H (1992) Voltage- and time-dependent inhibition of neuronal calcium channels by a GTP-binding protein in a mammalian cell line. J Physiol (Lond) 448:189-209.

Kasai H, Aosaki T (1989) Modulation of $\mathrm{Ca}^{2+}$ channel current by an adenosine analog mediated by a GTP-binding protein in chick sensory neurons. Pfluegers Arch Eur J Physiol 414:145-149.

Kleuss C, Hescheler J, Ewel C, Rosenthal W, Schultz G, Wittig B (1991) Assignment of G-protein subtypes to specific receptors inducing inhibition of calcium currents. Nature 353:43-48.

Lee KS, Tsien RW (1982) Reversal of current through calcium channels in dialyzed single heart cells. Nature 297:498-504.

Lipscombe D, Kongsamut S, Tsien RW (1989) Alpha-adrenergic inhibition of sympathetic neurotransmitter release mediated by modulation of N-type calcium-channel gating. Nature 340:639-642.

Lopez HS, Brown AM (1991) Correlation between G protein activation and reblocking kinetics of $\mathrm{Ca}^{2+}$ channel currents in rat sensory neurons. Neuron 7:1-20.

Marchetti C, Carbone E, Lux HD (1986) Effects of dopamine and noradrenaline on $\mathrm{Ca}^{2+}$ channels of cultured sensory and sympathetic neurons of chick. Eur J Physiol 406:104-111.

McCleskey EW, Fox AP, Feldman DH, Cruz LJ, Olivera BM, Tsien RW (1987) $\omega$-Conotoxin: direct and persistent blockade of specific types of calcium channels in neurons but not muscle. Proc Natl Acad Sci USA 84:4327-4331.

Nowycky MC, Fox AP, Tsien RW (1985) Three types of neuronal calcium channel with different calcium agonist sensitivity. Nature 316:440-443.

Plummer MR, Logothetis DE, Hess P (1989) Elcmentary properties and modulation of calcium channels in mammalian peripheral neurons. Neuron 2:1453-1464.

Plummer MR, Rittenhouse A, Kanevsky M, Hess P (1991) Neurotransmitter modulation of calcium channels in rat sympathetic neurons. J Neurosci 11:2339-2348.

Rane SG, Dunlap K (1986) Kinase C activator 1,2-OAG attenuates voltage-dependent current in sensory neurons. Proc Natl Acad Sci USA 83:184-188.

Rane SG, Walsh MP, McDonald JR, Dunlap K (1989) Specific inhibitors of protein kinase $C$ block transmitter-induced modulation of sensory neuron calcium current. Neuron 3:239-245.

Role LW (1988) Neural regulation of acetylcholine sensitivity in embryonic sympathetic neurons. Proc Natl Acad Sci USA 85:28252829.

Taussig R, Sanchez S, Rifo M, Gilman AG, Belardetti F (1992) Inhibition of the omega-conotoxin-sensitive calcium current by distinct $\mathrm{G}$ proteins. Neuron 8:799-809. 